\title{
Variability of MLT winds and waves over mid-latitude during the 2000/2001 and 2009/2010 winter stratospheric sudden warming
}

\author{
X. Chen ${ }^{1,2}$, X. Hu ${ }^{1}$, and C. Xiao ${ }^{1}$ \\ ${ }^{1}$ Center for Space Science and Applied Research, Chinese Academy of Sciences, Beijing, 100190, China \\ ${ }^{2}$ Graduate University of the Chinese Academy of Sciences, Beijing, 100049, China
}

Correspondence to: X. Hu (xhu@nssc.ac.cn)

Received: 1 December 2011 - Revised: 23 May 2012 - Accepted: 24 May 2012 - Published: 28 June 2012

\begin{abstract}
The mesosphere and lower thermosphere (MLT) wind structure over Wuhan $\left(30^{\circ} \mathrm{N}, 114^{\circ} \mathrm{E}\right)$ in $2000 / 2001$ winter and over Langfang $\left(39.4^{\circ} \mathrm{N}, 116.6^{\circ} \mathrm{E}\right)$ in $2009 / 2010$ winter are examined to reveal the effects of stratospheric sudden warming (SSW) in mid-low-latitude MLT region. The result shows that the MLT daily zonal wind over these two sites reversed from eastward wind to westward wind for several days during the SSW events. The reversals were almost coincident with the polar stratospheric temperature reaching its maximum at $10 \mathrm{hPa}, 90^{\circ} \mathrm{N}$ and were about ten days prior to the reversal of high latitude stratospheric zonal wind at $10 \mathrm{hPa}, 60^{\circ} \mathrm{N}$. The temporal variations of tides, gravity waves and 2-day planetary waves in the mid-latitude MLT showed different behavior during the two SSW events. During the 2001 SSW event, MLT diurnal tide reached its maximum when the MLT zonal wind decreased rapidly and SSW event began in polar stratosphere; the activity of 2-day waves decreased after the onset of the $2001 \mathrm{SSW}$, while the gravity wave increased when the $2001 \mathrm{SSW}$ developed into a major warming. However, in the 2009/2010 winter, the semidiurnal tide and 2-day wave in MLT over Langfang reached a peak about two days earlier than zonal wind reversal at $10 \mathrm{hPa}$, $60^{\circ} \mathrm{N}$; no significant features were found in diurnal tides, terdiurnal tides and gravity waves related to the 2010 SSW event.
\end{abstract}

Keywords. Meteorology and atmospheric dynamics (Middle atmosphere dynamics)

\section{Introduction}

The stratospheric sudden warming (SSW) event, first observed by Scherhag in 1952 (Scherhag, 1952), is a spectacular transient phenomenon in the high latitude winter which can influence the whole global atmosphere. It is characterized by a rapid increase of polar stratospheric temperature accompanied with a deceleration or even reversal of the eastward zonal winds. A major warming is defined as when the zonal-mean temperature at $10 \mathrm{hPa}$ or below increases poleward from $60^{\circ} \mathrm{N}$ (a reversal of temperature gradient) and the zonal-mean zonal wind becomes westward. A minor warming is when the temperature gradient reverses but the zonalmean zonal wind does not reverse and only becomes weakly eastward (Andrews et al., 1987). Major SSWs have been observed mainly in the Northern Hemisphere and only one or two times in a winter, while minor SSWs may occur several times in one winter and may even appear in the Southern Hemisphere. An SSW event involves profound changes of temperature, winds and circulation in a short time. Therefore, the SSW events provide a good way to investigate the coupling between middle atmosphere and lower atmosphere.

The evolution of SSW events at high latitude in stratosphere is well characterized and understood from extensive observations and research since 1952. The key mechanism of major SSW events is the growth of upward- propagating forced stationary planetary waves from the troposphere and their interaction with the mean flow in the middle atmosphere (Matsuno, 1971).

Numerous observations and case studies reported that the MLT winds and temperatures have significant changes at high latitude during SSW events. According to the observation at Resolute Bay, Canada $\left(74.9^{\circ} \mathrm{N}, 94.9^{\circ} \mathrm{W}\right)$, a reversal 
of eastward zonal winds happened several days before temperature maximum in the stratospheric polar cap during the SSW event in February 2001 (Bhattacharya et al., 2004). MLT winds observed at three other stations located at Castle Eaton, $52^{\circ} \mathrm{N}$; Collm, $52^{\circ} \mathrm{N}$ and Esrange, $68^{\circ} \mathrm{N}$ showed that both zonal and meridional winds changed directions in the mesopause region when the SSW event happened (Jacobi et al., 2003). A study by Hoffmann et al. (2007) showed a short-term reversal of the mesospheric winds followed by a period of strong eastward winds. Dowdy et al. (2007) investigated the response of the polar MLT atmosphere to seven major SSWs (including the February 2001 event) by using MF radars in the Antarctic and the Arctic. They found that on average the zonal winds reversed 4 days earlier in the MLT than in the stratosphere.

In recent years, some observations were carried out at tropical MLT region. Observations at Tirunelveli $\left(8.7^{\circ} \mathrm{N}\right.$, $77.8^{\circ} \mathrm{E}$ ) during three major SSW events showed that a reversal of zonal winds occurred several days before the onset of SSWs at high latitude (Sathishkumar et al., 2009). Mesospheric cooling and stratospheric warming were both observed at the tropics during SSW events (Shepherd et al., 2007).

MLT planetary wave activities during SSW events have also been investigated. Some case studies showed an enhancement of planetary wave 1 activity in the mesosphere at high latitudes during major warmings (Hoffmann et al., 2007). For the February 2001 SSW, the reversal of zonal component in MLT at Castle Eaton, Collm and Esrange was associated with a planetary-wave oscillation with a period of 10 days (Jacobi et al., 2003). Spectral analyses of South Pole $\mathrm{OH}$ airglow brightness measurements from the 1995 and 2002 winters showed amplification of the 4-day wave in the mesosphere preceding the onset of SSW events (Azeem et al., 2005).

Dowdy et al. (2007) found that the response of mesospheric gravity wave activity varied among different radar sites or different SSW events. Wang and Alexander (2009) found enhanced gravity wave amplitudes in the stratosphere and subdued gravity wave amplitudes in the lower mesosphere during the SSW events in 2007-2008 winter. They explained these variations with gravity wave propagation considerations. Sathishkumar and Sridharan (2009) investigated gravity wave activity with MF radar zonal winds at altitudes $84-98 \mathrm{~km}$ over Tirunelveli $\left(8.7^{\circ} \mathrm{N}, 77.8^{\circ} \mathrm{E}\right)$. They reported enhancement in gravity wave activity observed during 2005/2006 but not during 1998/1999, and the mean meridional winds changed to more equatorward during 2005-2006 but remained poleward during 1998-1999.

However, there are few reports (until now) devoted to the possible effects of SSW events below $40^{\circ} \mathrm{N}$ MLT atmosphere. It is believed that more observations about SSW events help us to understand the dynamics of stratospheric warmings, to interpret upward and downward vertical couplings in the winter atmosphere. In this paper, we use the
$2000 / 2001 \mathrm{MLT}$ winds data over Wuhan $\left(30^{\circ} \mathrm{N}, 114^{\circ} \mathrm{E}\right)$ and the $2009 / 2010$ MLT winds data over Langfang $\left(39.4^{\circ} \mathrm{N}\right.$, $\left.116.6^{\circ} \mathrm{E}\right)$ to investigate changes in the MLT over midlatitudes associated with SSW events. The prevailing winds, tides, gravity waves and planetary waves during the two SSW events were analyzed and compared with the observations in high latitudes.

\section{Data sources and data analysis methods}

\subsection{Data sources}

The MLT wind data used in this study were obtained from Wuhan $\left(30^{\circ} \mathrm{N}, 114^{\circ} \mathrm{E}\right) \mathrm{MF}$ radar and Langfang $\left(39.4^{\circ} \mathrm{N}\right.$, $\left.116.6^{\circ} \mathrm{E}\right) \mathrm{MF}$ radar. The MF radar provides measurements of the plasma drift velocity directly. In MLT below $100 \mathrm{~km}$, the neutral wind is almost equal to the ion drift velocity because the ratio of ion gyro frequency to the ion-neutral collision frequency is much less than 1 . Therefore, the MF radar wind is taken as the neutral wind for a simple assumption (Reid, 1983; Nozawa et al., 2002). However, above $100 \mathrm{~km}$ in MLT, due to the ratio becoming close to and much greater than 1, the ion drift velocity will become much different from the neutral winds (Oyama et al., 2012). The ion drag on the neutrals may induce neutral wind shear and even neutral instability (Hall and Aso, 2000).

Wuhan MF radar and Langfang MF radar used the "spaced antenna" (SA) systems and employed full correlation analysis techniques to routinely measure winds, just the same as the majority of MF radars in operations around the world. Wuhan MF radar, set up at the end of 2000, aims to observe the MLT winds from 60 to $98 \mathrm{~km}$ with $2 \mathrm{~km}$ height interval and 4 min time interval. It operated at a frequency of $2.01 \mathrm{MHz}$ with $25 \mathrm{~kW}$ peak transmitting power, and it was configured with a transmitting antenna of squared dipoles and three receiving antenna of crossed dipoles ( $\mathrm{Li}$ et al., 2002). With Wuhan MF radar data, Zhang et al. (2004) analyzed winds and tides of winter mesopause region; Hu et al. (2006) made a comparison between Wuhan MF radar and Yamagawa MF radar. Langfang MF radar was configured with four antennas arranged in an almost equilateral triangle. Langfang MF radar operates at a frequency of $1.99 \mathrm{MHz}$ with $64 \mathrm{~kW}$ peak transmitting power. It observes the MLT winds from 60 to $110 \mathrm{~km}$ with a $2 \mathrm{~km}$ height interval and 4 min time interval. The integration time for one wind profile measurement is $104 \mathrm{~s}$. It provides MLT horizontal wind data ever since May 2009.

We collected Wuhan MF radar wind data in 2000/2001 winter and Langfang MF radar wind data since May 2009. Therefore, these wind data help us to reveal the relations between SSW and variability of MLT winds and waves over mid-latitude during 2000/2001 winter and 2009/2010 winter.

For the $2001 \mathrm{SSW}$ event, the data series used to investigate the variations of MLT winds are from 22 December 2000 to 
15 March 2001. For the 2010 SSW event, the MLT winds data series are from 29 December 2009 to 15 March 2010. Since there is no data below $80 \mathrm{~km}$ in the night due to the disappearance of the ionosphere D layer, only horizontal winds from 80 to $98 \mathrm{~km}$ were used.

To reveal the evolution of these two SSW events, we used winds and temperature data from NCEP/NCAR Reanalysis project from 25 December 2000 to 15 March 2001 and from 21 December 2009 to 15 March 2010. For more details about the 2010 SSW event, the geopotential height data of Aura Microwave Limb Sounder (MLS) were used to derive the zonal gradient wind in the height range of 10 to $70 \mathrm{~km}$ in 2009/2010 winter. The Aura satellite was launched on 15 July 2004 in a near polar, sun-synchronous orbit with a period of approximately $100 \mathrm{~min}$.

\subsection{Data analysis}

The MLT daily mean winds, tides, gravity waves and 2-day planetary waves were estimated from radar data. In order to get daily mean winds over the two sites, we firstly calculated hourly mean winds in each 1-h bin for each height. Then the hourly mean winds in 1-day were averaged to get the daily mean winds. Considering the data gaps due to power off or instrument reasons, it required at least 16 hourly mean winds in one day at a given height to estimate the daily mean winds. Figure 1 shows the data gaps in hourly mean wind data of Wuhan MF radar in 2000/2001 winter and Langfang MF radar in 2009/2010 winter. Black means data missing in that hour.

MLT winds are mostly composed of background winds and wavelike variations, including tides, planetary waves and gravity waves. According to current researches (e.g. Zhang et al., 2004; Hocke and Igarashi, 1999), tide wave with period of $24 \mathrm{~h}, 12 \mathrm{~h}$ are the most dominant components in MLT region. Amplitude of the 8-h (terdiurnal) tide is also significant (e.g. Jiang et al., 2009). However, the tide amplitudes with periods equal to or less than $6 \mathrm{~h}$ are relatively small in some observations and not always found in analysis of time series (e.g. Oznovich et al., 1997; Kovalam and Vincent, 2003; Smith et al., 2004). Therefore, we suppose that the major periods of tides are $24 \mathrm{~h}, 12 \mathrm{~h}$ and $8 \mathrm{~h}$, while the 6-h tide is not considered here. In this paper, diurnal tides, semidiurnal tides, terdiurnal tides and 2-day planetary waves were derived by applying harmonic fitting to the time series of hourly mean winds. The data window was $96 \mathrm{~h}$ (4 days) in each fitting and it shifted with a 1-h time step. It required at least $72 \mathrm{~h}$ of hourly mean winds in a 96-h window for a given height in each fitting. The amplitudes and phases of tides and 2-day waves were obtained by fitting Eq. (1) with the least square method:

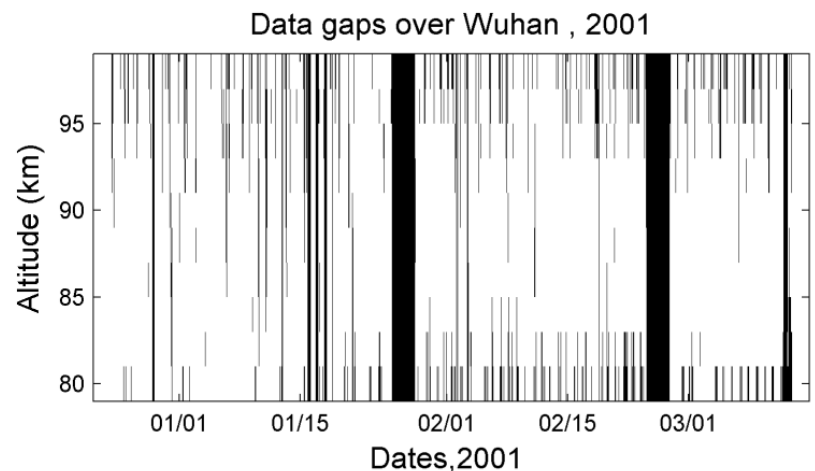

(a)

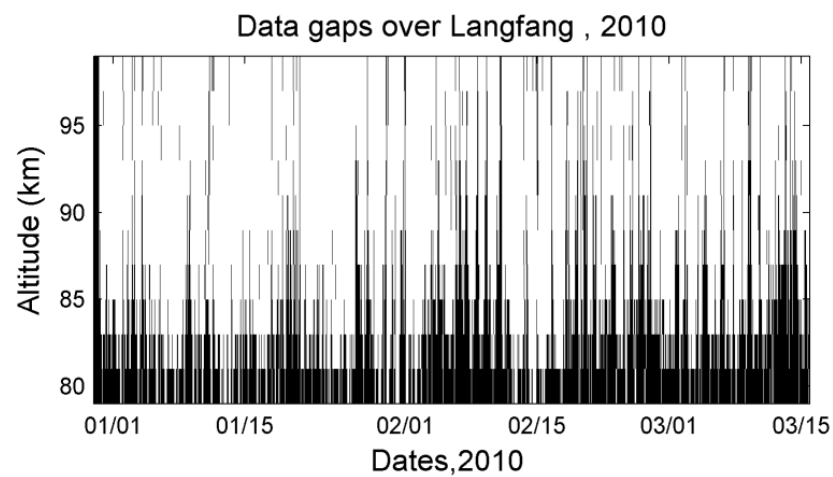

(b)

Fig. 1. (a) Data gaps in hourly mean wind data of Wuhan MF radar in 2000/2001 winter and (b) data gaps in hourly mean wind data of Langfang MF radar in 2009/2010 winter. Black means data missing in that hour.

$$
\begin{aligned}
u(t)= & u_{0}+a \cdot \cos \left(\frac{2 \pi t}{24}-\theta_{24}\right)+b \cdot \cos \left(\frac{2 \pi t}{12}-\theta_{12}\right) \\
& +c \cdot \cos \left(\frac{2 \pi t}{8}-\theta_{8}\right)+d \cdot \cos \left(\frac{2 \pi t}{48}-\theta_{48}\right)
\end{aligned}
$$

where $u(t)$ is the hourly mean wind, and $a, b, c, d$ are amplitudes, $\theta_{24}, \theta_{12}, \theta_{8}, \theta_{48}$ are phases, $t$ is time in hour, and $u_{0}$ is the background wind. In the right side of Eq. (1), the constant " $u_{0}$ " may include the background wind and long-term planetary waves (greater than 4 days).

After fitting, the root mean square (RMS) of the residual wind was obtained by calculating the difference between the hourly winds $u(t)$ and the fitted value $u^{\prime}(t)$. This RMS represents mostly gravity wave perturbations with periods longer than two hours. The RMS velocities also include contributions from noise and tides with $6-\mathrm{h}$ period or interacting waves (Haldoupis et al., 2004).

The gradient wind in 2009/2010 winter was calculated from geopotential height data of Aura MLS. The method was similar to what Xiao et al. (2008) and Remsberg et al. (2003) did in their papers. The main formulas are as follows: 
$u_{\mathrm{g}}=-\frac{g 0}{f a} \frac{\partial H}{\partial \varphi}$

$u_{\mathrm{gr}}=-M+\left(M^{2}+2 M \times u_{\mathrm{g}}\right)^{1 / 2}$.

Where $u_{\mathrm{g}}$ represents the geostrophic wind, $u_{\mathrm{gr}}$ represents the gradient wind, $M$ is the tangential velocity of Earth rotation and can be calculated by $M=a \Omega \cos \varphi . g 0$ is the mean gravitational acceleration, $f$ is the Coriolis parameter, $a$ is Earth radius $(6378 \mathrm{~km}), H$ is geopotential height, $\varphi$ is latitude, $\Omega$ is the Earth's rotation rate. Here, we firstly applied the spherical harmonics fitting to the geopotential height data in each pressure level in each day, and then calculated the gradient wind by formula (2) and formula (3), resulting in $2.5 \times 2.5$ degree grids in the Northern Hemisphere.

Since the Aura satellite is operated in the near polar, sunsynchronous orbit, the obtained data are distributed near two local times in a given day. Thus, the gradient winds derived from them just represent the averages of those local times. Considering the influences of the tidal waves in MLT region and the limitation of the data distribution, we adopted the gradient wind between $10 \sim 70 \mathrm{~km}$ and $20^{\circ} \mathrm{N} \sim 70^{\circ} \mathrm{N}$ in the analysis section.

\section{Results}

\subsection{Features of the SSW event in 2000/2001 winter and variability of the mid-low-latitude MLT winds}

NCEP wind and temperature reanalysis data at $10 \mathrm{hPa}$ in the northern polar region were used to reveal the evolution of the SSW events. Figure 2 shows the evolution of the 2001 SSW event and the daily mean zonal wind at $90 \mathrm{~km}$ over Wuhan in the 2000/2001 winter. During the 2001 SSW event, Fig. 2a shows that the zonal mean zonal wind at $60^{\circ} \mathrm{N}, 10 \mathrm{hPa}$ decreased rapidly after 15 January 2001 and finally reversed after 11 February 2001, and then westward wind reached its maximum on 18 February 2001. The westward wind turned back to eastward wind after 24 February 2001. The temperature at $10 \mathrm{hPa}$ over the polar region increased from $15 \mathrm{Jan}-$ uary 2001 and peaked on 2 February 2001, as shown in Fig. 2c. The temperature difference between $90^{\circ} \mathrm{N}$ and $60^{\circ} \mathrm{N}$ at $10 \mathrm{hPa}$ (Fig. 2b) peaked on 2 February 2001 and 18 February 2001 . The polar stratospheric temperature at $10 \mathrm{hPa}$ increased by more than $40 \mathrm{~K}$ within two weeks and then the warm conditions persisted for about 3 weeks. The amplitude of stationary planetary waves with zonal wave number 1 (SPW1) increased rapidly from early of Jan and peaked on 2 February 2001, while the amplitude of stationary planetary waves with zonal wave number 2 (SPW2) began to grow from the end of January and peaked on 15 February 2001. After 24 February 2001, the zonal mean zonal wind and temperature gradient changed back to normal winter condition,

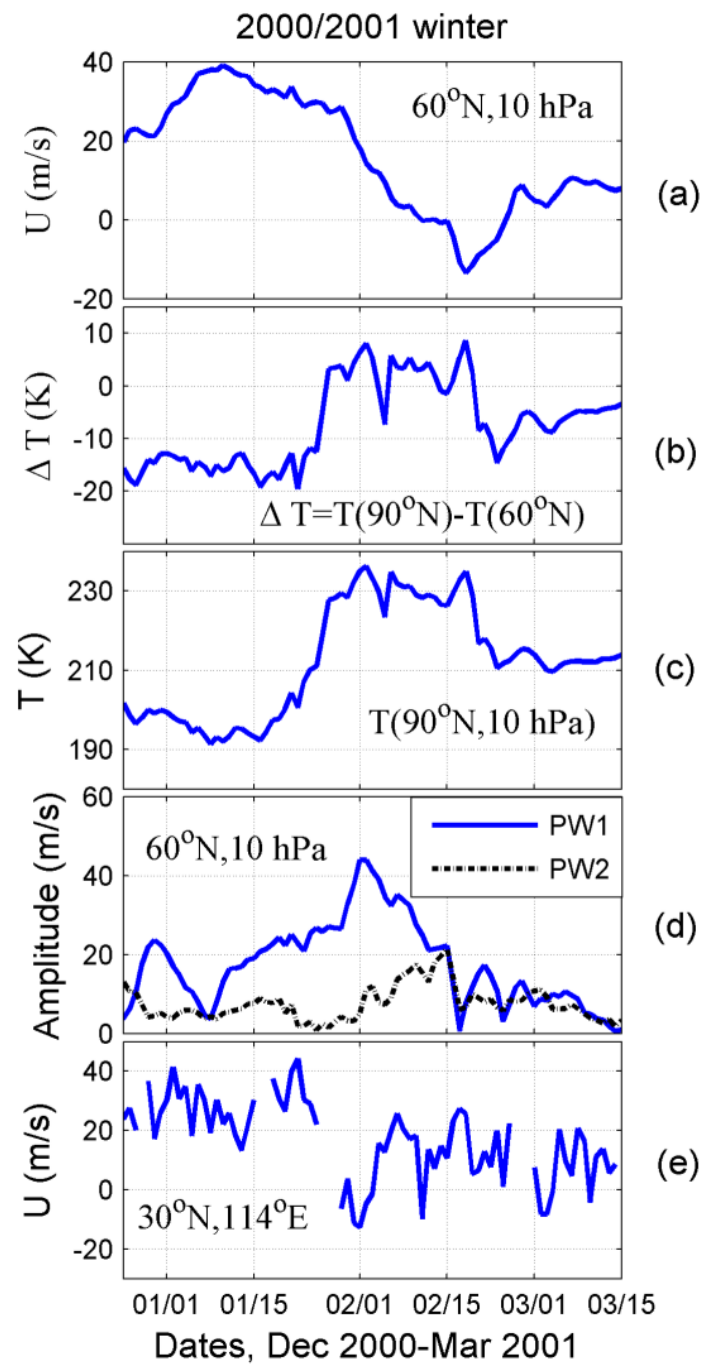

Fig. 2. The evolution of the $2001 \mathrm{SSW}$ event and daily mean zonal wind over Wuhan. (a) Zonal mean zonal wind at $60^{\circ} \mathrm{N}, 10 \mathrm{hPa}$. (b) Zonal mean temperature difference between $90^{\circ} \mathrm{N}, 10 \mathrm{hPa}$ and $60^{\circ} \mathrm{N}, 10 \mathrm{hPa}$. (c) Temperature at $90^{\circ} \mathrm{N}, 10 \mathrm{hPa}$. (d) Amplitudes of SPW1 (blue solid line) and SPW2 (black dotted line) at $60^{\circ} \mathrm{N}$, $10 \mathrm{hPa}$. (e) Daily mean zonal wind at $90 \mathrm{~km}$ over Wuhan.

indicating the end of this major warming event. As seen in Fig. 2a, strictly according to the definition of the World Meteorological Organization (WMO), the major warming persisted from 11 February 2001 to 24 February 2001, when both zonal mean zonal wind and temperature gradient reversed signs. Actually, this SSW event started around 15 January 2001 and ended around late February. Bhattacharya et al. (2004) revealed the 2001 SSW event with the data at $3.16 \mathrm{hPa}$. They reported this event began around $17 \mathrm{Jan}-$ uary 2001, and reached the temperature peak around 1 February 2001 .

At the first peak of polar stratospheric temperature (around 1 February 2001), a zonal wind reversal in MLT over Wuhan 


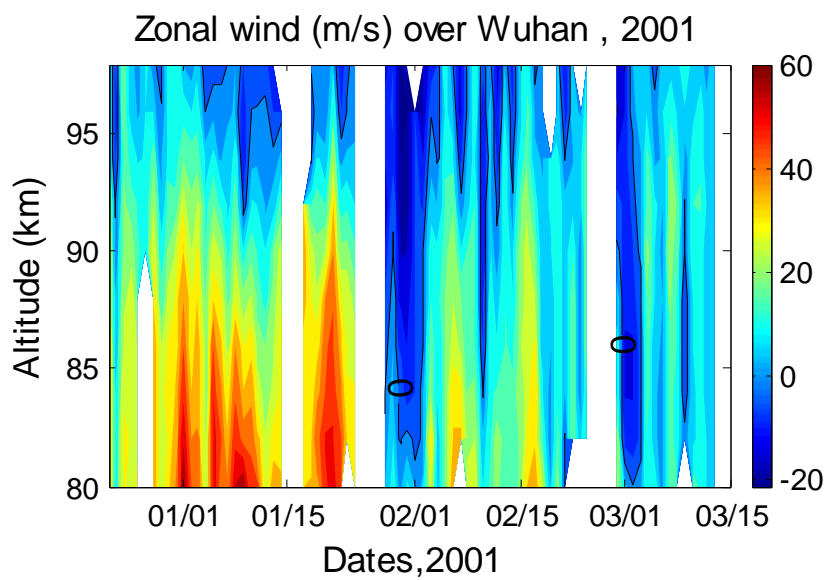

(a)

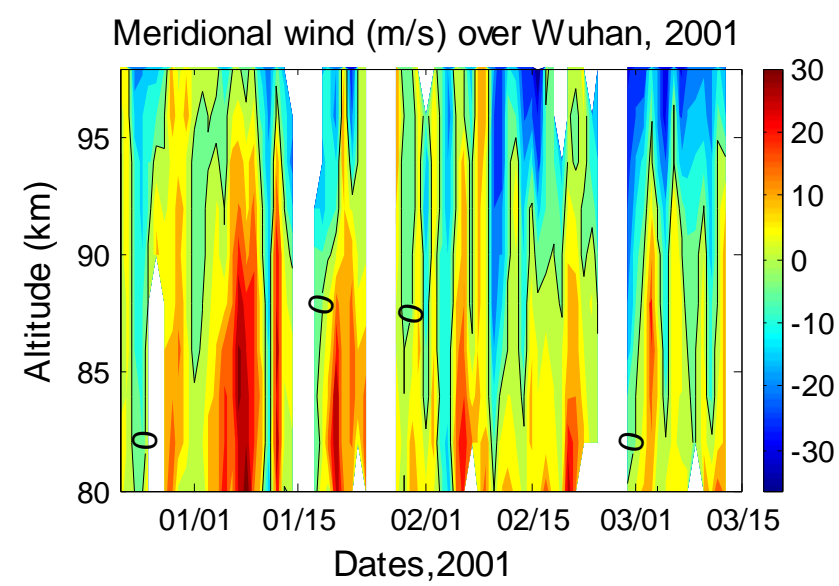

(b)

Fig. 3. The daily mean zonal (a) and meridional (b) winds observed at Wuhan in the height range of 80 to $98 \mathrm{~km}$ in 2000/2001 winter. The black lines represent zero wind. Eastward and northward are positive.

is clearly seen at $90 \mathrm{~km}$, as shown in Fig. 2e. On 22 January 2001, the daily mean eastward wind almost reached $41 \mathrm{~m} \mathrm{~s}^{-1}$. After several days of eastward deceleration, the zonal wind reversed into westward wind with a maximum value larger than $16 \mathrm{~m} \mathrm{~s}^{-1}$ on 31 January 2001. It means the zonal wind at $90 \mathrm{~km}$ over Wuhan changed in $57 \mathrm{~m} \mathrm{~s}^{-1}$ in ten days. The deceleration of the mid-low-latitude MLT eastward jet coincided with the polar temperature increasing and SPW1 growth period.

Figure 3 shows the daily mean zonal and meridional wind structure observed at Wuhan in the height range of 80 to $98 \mathrm{~km}$ during the period of 22 December 200015 March 2001. In Fig. 3a, we can see that from the end of 2000 to the first month of 2001, the eastward wind dominated below $96 \mathrm{~km}$ and increased with decreasing altitude. Weak eastward and even westward winds appeared above $96 \mathrm{~km}$. Yet a pronounced reversal of the MLT eastward winds occurred from late January to early February, which could be relevant to this SSW event. The strong eastward zonal winds reversed to westward winds around 1 February 2001. At the same time, the eastward winds at $10 \mathrm{hPa}$ decreased sharply and the temperature gradient reversed while the amplitude of SPW1 reached its maximum (Fig. 2d), then the zonal winds resumed quickly to eastward. There were two other weak and short-time zonal wind reversals occurring around 10 February 2001 and 2 March 2001. The reversal on 10 February 2001 is likely to be due to the enhancement of amplitude of SPW2 and the reversal around 2 March 2001 might connect to season change. As the spring came in March, the zonal wind became weakly eastward or westward.

Complex day-to-day variations in the 2000/2001 winter meridional winds over Wuhan were shown in Fig. 3b. Relatively, the equatorward wind dominated at lower altitudes and showed strong southward winds (reversals of poleward wind) around 1 February and 10 February 2001 below 90 km, concurrent with the zonal winds reversals.

The temporal variations of horizontal winds in MLT at higher latitudes above $50^{\circ} \mathrm{N}$ showed similar features for the same winter of 2000/2001 (Bhattacharya et al., 2004; Jacobi et al., 2003). They both observed a clear reversal of eastward zonal winds related to the same SSW event in 2001. However, the temporal evolution of the zonal winds and meridional winds at different stations still had different detailed features which should not be neglected. The zonal winds over Castle Eaton $\left(52^{\circ} \mathrm{N}, 2^{\circ} \mathrm{W}\right)$, Collm $\left(52^{\circ} \mathrm{N}\right.$, $\left.15^{\circ} \mathrm{E}\right)$ and Esrange $\left(68^{\circ} \mathrm{N}, 21^{\circ} \mathrm{E}\right)$ reversed from 14 February to 24 February 2001, showing a response coincident with the major phase of this SSW. While at Resolute Bay $\left(74.9^{\circ} \mathrm{N}, 94.9^{\circ} \mathrm{W}\right)$, there was an apparent sharp reversal of zonal winds around 1 February 2001 and a slight reversal on 10 February 2001, almost consistent with our results. The differences in MLT winds among different sites may be due to latitudinal and longitudinal discrepancies. More observations and model simulations will help us to have a global view of the MLT response to SSW events.

\subsection{Features of the SSW event in $2009 / 2010$ winter and variability of the mid-latitude MLT winds}

Figure 4 shows the evolution of the 2010 SSW event and the daily mean zonal wind at $90 \mathrm{~km}$ over Langfang in the 2009/2010 winter. The 2010 SSW event started around 18 January 2010 and showed similar characteristics to 2001 SSW event. The zonal mean zonal wind at $60^{\circ} \mathrm{N}, 10 \mathrm{hPa}$ decreased rapidly from around 18 January 2010 and finally reversed during the period of 9 February- 11 February 2010 and 20 February-24 February 2010, as shown in Fig. 4a. The westward wind peaked on 10 February 2010. The temperature at $90^{\circ} \mathrm{N}, 10 \mathrm{hPa}$ increased quickly since $18 \mathrm{Jan}-$ uary 2010 and peaked on 29 January 2010 with the maximum value larger than $235 \mathrm{~K}$; while the temperature gradients between $90^{\circ} \mathrm{N}$ and $60^{\circ} \mathrm{N}$ peaked on 22 January 2010 and kept the reversal meridional temperature gradient till 


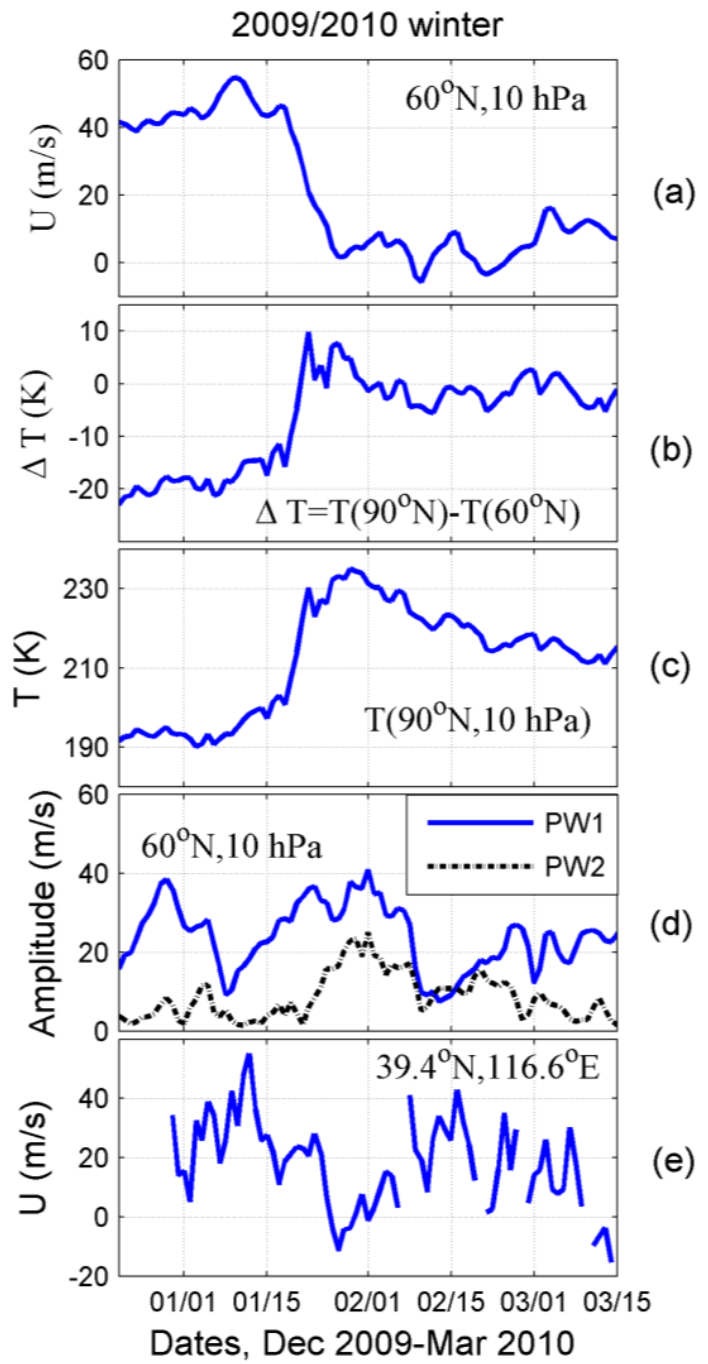

Fig. 4. The evolution of the 2010 SSW event and daily mean zonal wind over Langfang. (a) Zonal mean zonal wind at $60^{\circ} \mathrm{N}, 10 \mathrm{hPa}$. (b) Zonal mean temperature difference between $90^{\circ} \mathrm{N}, 10 \mathrm{hPa}$ and $60^{\circ} \mathrm{N}, 10 \mathrm{hPa}$. (c) Temperature at $90^{\circ} \mathrm{N}, 10 \mathrm{hPa}$. (d) Amplitudes of SPW1 (blue solid line) and SPW2 (black dotted line) at $60^{\circ} \mathrm{N}$, $10 \mathrm{hPa}$. (e) Daily mean zonal wind at $90 \mathrm{~km}$ over Langfang.

February. The amplitudes of SPW1 and SPW2 of zonal wind at $60^{\circ} \mathrm{N}, 10 \mathrm{hPa}$ enhanced since 18 January 2010 and peaked on 1 Febraury 2010, as shown in Fig. 4. It seems that the onset of the two SSW events was accompanied by the enhancement of SPW1 and they finally developed into a major warming after SPW 2 reached its maximum.

From Fig. 4e, an obvious reversal of daily mean zonal wind at $90 \mathrm{~km}$ over Langfang $\left(39.4^{\circ} \mathrm{N}, 116.6^{\circ} \mathrm{E}\right)$ is found at the early stage of the $2010 \mathrm{SSW}$ event. The MLT eastward wind almost reached $55 \mathrm{~m} \mathrm{~s}^{-1}$ on 12 January 2010 and then decreased tens $\mathrm{m} \mathrm{s}^{-1}$ in about 15 days. It finally reversed to westward wind with a maximum value larger than $11 \mathrm{~m} \mathrm{~s}^{-1}$
(a)Zonal wind $(\mathrm{m} / \mathrm{s})$ over Langfang, MF radar data

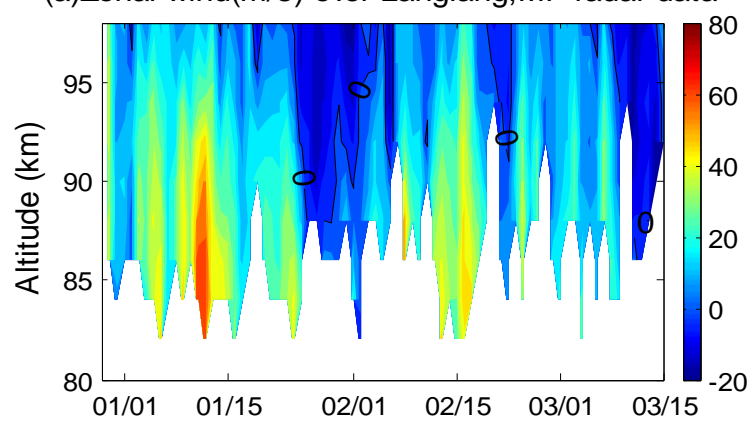

(b)Zonal mean zonal gradient wind $(\mathrm{m} / \mathrm{s})$ at $40^{\circ} \mathrm{N}$

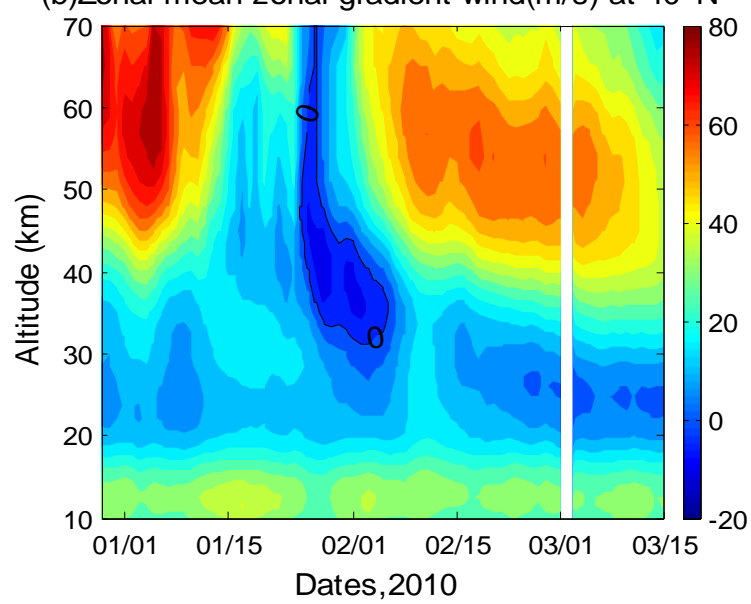

Fig. 5. (a) The daily mean zonal wind observed at Langfang in the height range of 80 to $98 \mathrm{~km}$ and (b) zonal mean zonal gradient wind over $40^{\circ} \mathrm{N}$ in the height range of 10 to $70 \mathrm{~km}$ in 2009/2010 winter. The black lines represent zero wind. Eastward and northward are positive.

on 27 January 2010, about the same time polar temperature reached its peak at $10 \mathrm{hPa}$ on 29 January 2010 .

For more details, Fig. 5a shows the daily mean zonal wind observed at Langfang by MF radar in the height range of 80 to $98 \mathrm{~km}$ during the period of 29 December 200915 March 2010. In order to make a comparison, in Fig. 5b we plotted the zonal mean zonal gradient wind obtained from Aura MLS geopotential height data in the height range of 10 to $70 \mathrm{~km}$. From Fig. 5a, it is immediately evident that a significant reversal of Langfang MLT zonal winds related to the 2010 SSW event were from 24 January 2010 to 6 February 2010. At the same time, the zonal mean zonal gradient winds also decelerated and reversed in lower mesosphere and upper stratosphere $(40-70 \mathrm{~km})$, and then the reversal height extended downward into the stratosphere (about $30 \mathrm{~km}$ ) after several days. Figure 7 shows the zonal mean zonal wind at the winter hemisphere on 10 January (before SSW), 28 January (warming peak) and 10 February 2010 (westward wind maximum at $10 \mathrm{hPa}, 60^{\circ} \mathrm{N}$ ). On $10 \mathrm{Jan}$ uary 2010 before SSW event, the eastward wind is the dominant wind in middle and upper atmosphere. The eastward jet 


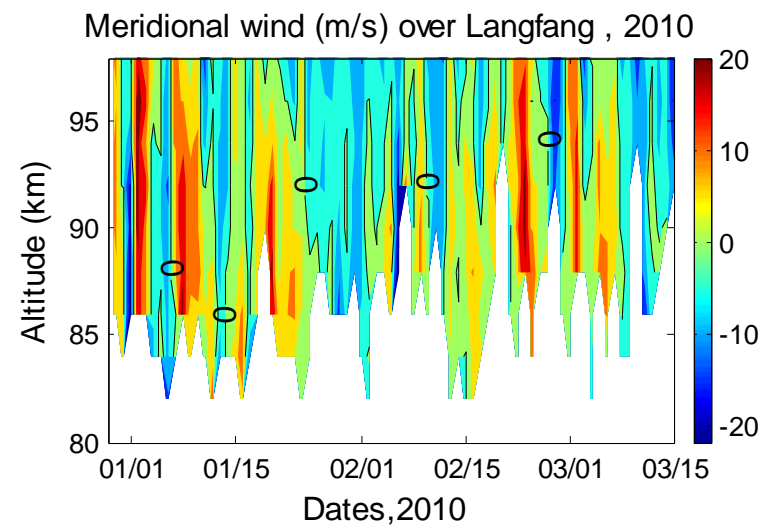

Fig. 6. The daily mean meridional winds observed at Langfang in the height range of 80 to $98 \mathrm{~km}$ in 2009/2010 winter. The black lines represent zero wind. Northward are positive.

core peaked at about $50 \mathrm{~km}$ and over $55^{\circ} \mathrm{N}$ and the eastward wind increased with altitude at mid-low-latitude. On 28 January 2010, zonal wind in stratosphere and mesosphere reversed to westward wind and the zero wind line at $70 \mathrm{~km}$ was near $40^{\circ} \mathrm{N}$. The lower mesosphere eastward wind over midlow-latitude was reduced greatly compared to 10 January. On 10 February 2010, the zonal wind in lower stratosphere reversed to westward wind while the wind in upper stratosphere and mesosphere returned to eastward wind. The MLT meridional wind over Langfang also changed from poleward to equatorward and the reversal lasted from 24 January 2010 to 6 February 2010, as shown in Fig. 6. The MLT reversal process almost coincided with the stratospheric polar temperature warming, SPW1 growth and the rapid deceleration of stratospheric polar eastward wind, but it is about ten days prior to the reversal in stratospheric polar zonal wind. It was a clear evolution that the 2010 SSW event started in MLT, almost covered the mid-low-latitude to pole, and then extended to downward and poleward.

\subsection{Responses of the mid-low-latitude mesospheric wave activities}

Diurnal, semidiurnal and terdiurnal tides obtained from harmonic fitting of 2001 MF hourly mean wind data over Wuhan at $90 \mathrm{~km}$ heights were shown in Fig. 8a. The temporal variations of the tides suggested that the diurnal tide was the dominant component in the 2000/2001 winter over Wuhan. Distinctive day-to-day variability of tidal amplitudes was seen at each height. The zonal and meridional amplitudes of diurnal tides showed a clear peak around 18 January 2001. Moreover, the amplitudes of diurnal tides enhanced and were followed by the SPW 1 growth at $60^{\circ} \mathrm{N}, 10 \mathrm{hPa}$ after 10 January 2001 . The magnitude of tidal amplitude fluctuations was up to several tens $\mathrm{m} \mathrm{s}^{-1}$ with planetary wave scale periods, suggesting interactions among planetary waves and tides. However, temporal spectra of tides did not show similar periods at each al-

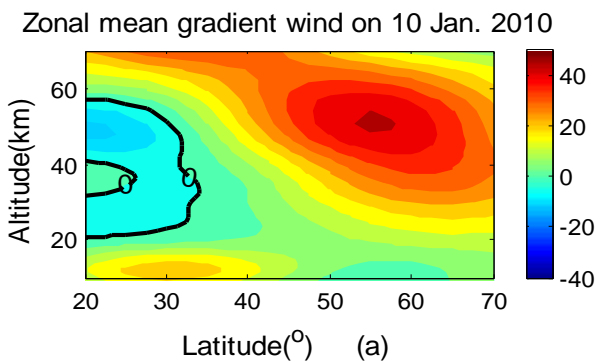

Zonal mean gradient wind on 28 Jan. 2010

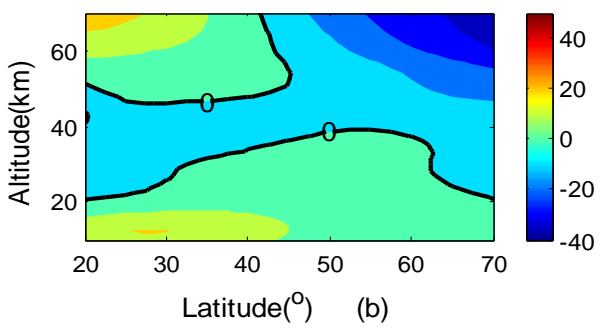

Zonal mean gradient wind on 10 Feb. 2010

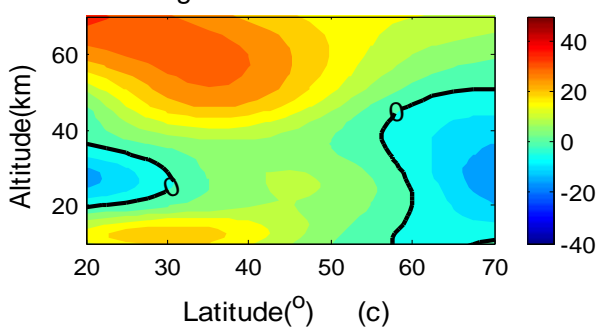

Fig. 7. Zonal mean zonal gradient wind on (a) 10 January 2010, (b) 28 January 2010 and (c) 10 Febuary 2010. The black lines represent zero wind. Eastward are positive.

titude. The amplitudes of semidiurnal tide and the periods of their variations over Castle Eaton, Collm and Esrange were also different from each other and from ours (Jacobi et al., 2003). At $94 \mathrm{~km}$ the tidal amplitude increased over Esrange but decreased over Collm during the major phase of this SSW event. The periods of the diurnal tidal amplitude variations were about 11-14 days and 20 days over Castle Eaton and Collm, respectively. In our result only 10-day oscillation is visible at some heights.

Figure 8 also gives amplitudes of 2-day waves and the RMS velocities for gravity wave activity with periods longer than two hour. From Fig. 8b, the detailed behavior suggested great fluctuation in the RMS velocities mainly caused by gravity waves during this SSW event (between the late January and late February), especially the zonal component in MLT region. The amplitudes of the 2-day planetary waves showed complex day-to-day variations. Relatively, the amplitudes weakened after the polar region temperature rise at $10 \mathrm{hPa}$. However, they did not show clear variations related to the 2001 SSW and the Wuhan MLT wind reversal.

Figure 9 shows tides, 2-day waves, RMS velocities of gravity waves and prevailing wind over Langfang at $90 \mathrm{~km}$ height. In the 2009/2010 winter, tidal temporal variations 
(a).Zonal(left) and meridional(right) amplitudes of tides (m/s)at 90km,WH,2000/2001
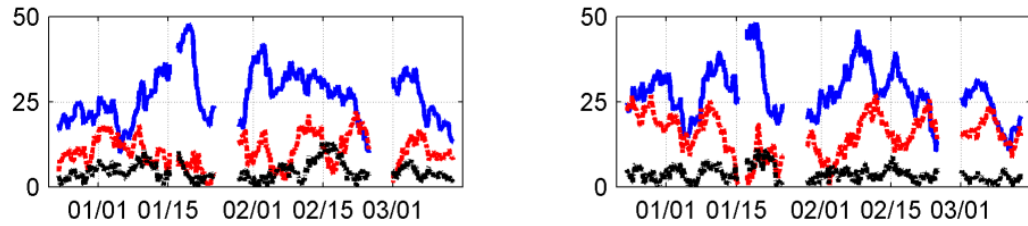

(b).Zonal(left) and meridional(right) RMS velocity of gravity wave (m/s)
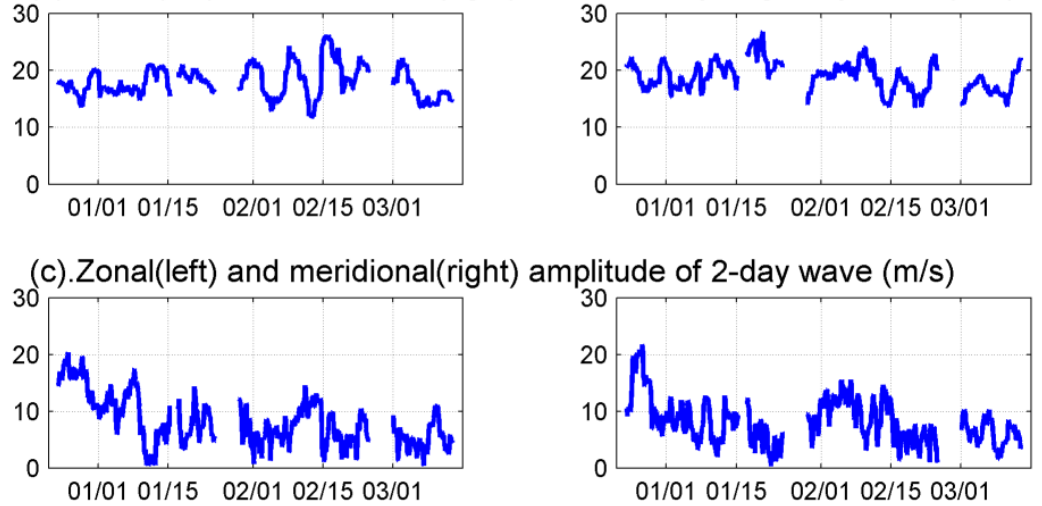

(d).Zonal(left) and meridional(right) prevailing wind ( $\mathrm{m} / \mathrm{s})$
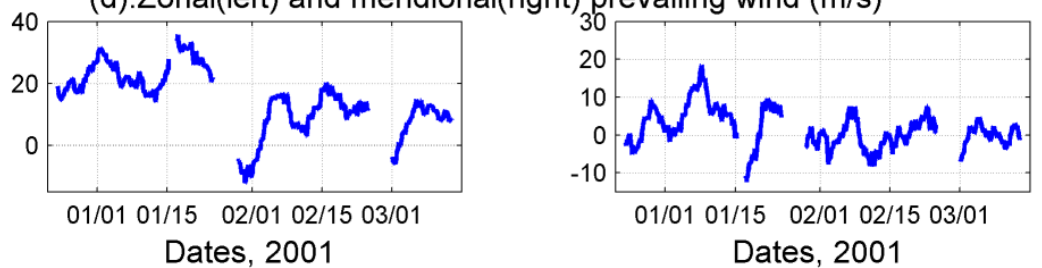

Fig. 8. Temporal variation of (a) tides, (b) gravity waves, (c) 2-day waves and (d) prevailing winds obtained from harmonic analysis at $90 \mathrm{~km}$ hourly mean winds over Wuhan during the period of 22 December 2000-15 March 2001. For the tides, diurnal, semidiurnal and terdiurnal tides are blue, red and black, respectively.

of MLT winds over Langfang showed that semidiurnal tide and diurnal tide were both important components. The diurnal amplitude of zonal wind was sometimes about $15 \mathrm{~m} \mathrm{~s}^{-1}$ larger than meridional component at $90 \mathrm{~km}$. The diurnal and semidiurnal tides decayed when the polar stratospheric temperature reached its maximum and the MLT zonal winds reversed into westward winds over Langfang from late January to early February 2010. The zonal and meridional amplitudes of semidiurnal tides peaked on 7 February 2010, coincident with the zonal wind resuming into eastward wind.

According to the gravity wave RMS velocity plot in Fig. 9b, there were no significant distinctive variability in gravity wave activity related to the 2010 SSW event or the Langfang MLT wind reversals. The 2-day planetary wave of zonal wind was similar with the semidiurnal tides. It also reached a minimum around late Jan and showed a clear peak on 7 February 2010, about two days earlier than the zonal wind reversal at $10 \mathrm{hPa}, 60^{\circ} \mathrm{N}$. The meridional component of 2-day waves was similar with the zonal one to a large extent.
The temporal variations of tides, gravity waves and 2-day planetary waves in MLT over Wuhan in 2000/2001 winter were different from those over Langfang in 2009/2010 winter. When the MLT winds started to decrease rapidly and SSW phenomenon began in Polar Regions around 15 January 2001, the diurnal tide showed a clear peak while the 2day wave began to decay, respectively. The activity of gravity increased at the late stage of the 2001 SSW event. However, in the 2009/2010 winter, after a depression periods around late January, the semidiurnal tide and 2-day waves reached their peaks on 7 February 2010, about two days earlier than the zonal wind reversal at $10 \mathrm{hPa}, 60^{\circ} \mathrm{N}$. No significant features were found in other wave components relating to the 2010 SSW event.

\section{Discussion}

In the 2000/2001 and 2009/2010 winter, the MLT winds over mid-latitude reversed when the temperature at $10 \mathrm{hPa}$, $90^{\circ} \mathrm{N}$ reach the maximum. This reversal was about ten days prior to the stratospheric winds reversal at $10 \mathrm{hPa}, 60^{\circ} \mathrm{N}$. The 
(a).Zonal(left) and meridional(right) amplitudes of tides (m/s) at 90km,LF,2009/2010
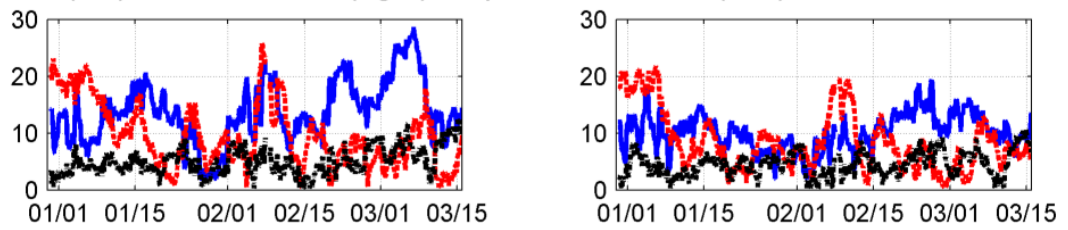

(b).Zonal(left) and meridional(right) RMS velocity of gravity wave $(\mathrm{m} / \mathrm{s})$
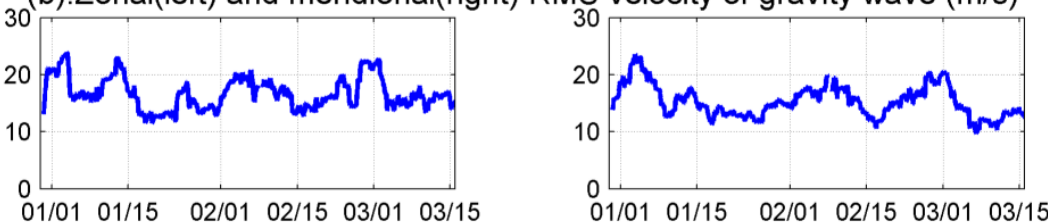

(c).Zonal(left) and meridional(right) amplitude of 2-day wave ( $\mathrm{m} / \mathrm{s})$
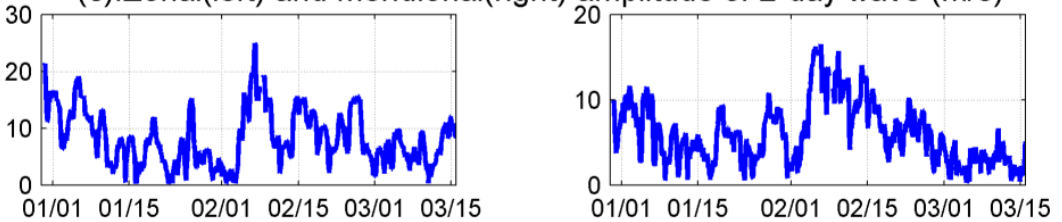

(d).Zonal(left) and meridional(right) prevailing wind $(\mathrm{m} / \mathrm{s})$
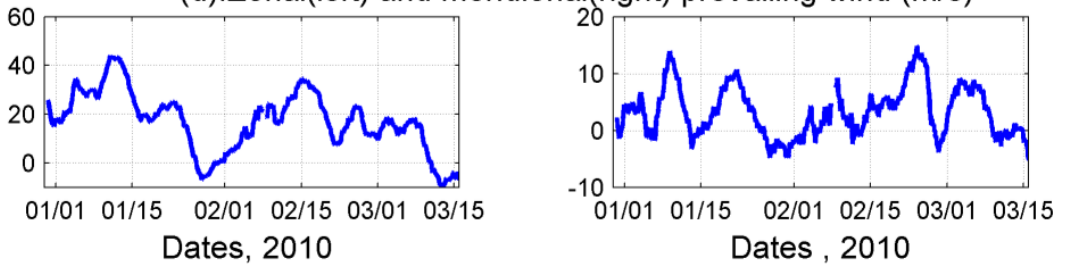

Fig. 9. Temporal variation of (a) tides, (b) gravity waves, (c) 2-day waves and (d) prevailing winds at 90 km over Langfang during the period of 29 December 2009-15 March 2010. For tides wave panel: diurnal, semidiurnal and terdiurnal tides are blue, red and black, respectively.

atmosphere waves showed different variability during the two SSW events. It suggests SSW events in the winter northern Polar Region have profound effects on MLT winds in the whole Northern Hemisphere. Moreover, in reference to these SSW events, their temperature gradient reversal at $10 \mathrm{hPa}$, zonal wind reversal at $1 \mathrm{hPa}$ and almost together with a first minimum of zonal wind at $10 \mathrm{hPa}$ occurred near 2 February 2001 and near 28 January 2010 . Though it was not a major warming at these times, according to the WMO definition these dates might belong to the center dates of these events in fact. If under this definition, the response of MLT wind over Wuhan and Langfang were simultaneous with SSW events in polar stratosphere.

The mesospheric response to SSW has widely been investigated in the high latitudes with ground measurements data and model simulations. However, there are few observation evidences and model results show mesospheric response in the mid-low latitudes until now. It is difficult to conceive that the mesospheric wind will reverse in the mid-low latitudes which are far from the polar stratosphere where the major warming event happens, especially almost at the same time.
The SSW events arise as a consequence of the wave-mean flow interaction when the planetary waves propagate upward into a critical layer (usually a critical layer is a critical line of zero wind in the upper mesosphere). First, the wavemean flow interaction takes place when the upward propagating planetary wave encounters the critical layer in the upper mesosphere. This interaction forces the high-altitude zonal winds flow to reverse from normal eastward to westward speeds (Liu and Roble, 2002; Matsuno, 1971). This reversal of zonal winds decreases the height of the critical layer of vertically propagating planetary waves; therefore, reduces the vertical propagation of later planetary waves. These forced planetary waves interact with the mean flow at lower altitudes where subsequently the reversals of zonal winds take place. It is believed that with strong enough and continued planetary wave forcing, the process of downward reversal will reach lower stratosphere and finally develop into a stratospheric sudden warming event (Meriwether and Gerrard, 2004). This is the reason why the reversal of zonal winds in MLT precedes the reversal of zonal winds in stratosphere, as shown in Fig. 7a, b, c. A poleward and downward residual circulation and adiabatic warming in the 
stratosphere are also induced by the westward forcing due to planetary waves in winter stratosphere.

The above theory and corresponding simulations can clearly interpret the observed MLT winds reversal at high latitudes. But it does not mean that the reversal of winds in MLT over mid-latitude during SSW event is clear. The reversal of zonal winds in MLT region over Wuhan and Langfang might be attributed to multiple factors. Generally, the zero wind surface of the Northern Hemisphere is near the equator in winter (Matsuno, 1970). Therefore, at mid-lowlatitude, it has a strong eastward wind in the upper stratosphere, mesosphere and lower thermosphere, as shown in Figs. 7a and 5. The zonal winds over Wuhan and Langfang in winter MLT region are eastward in contrast to that in the high latitudes which can allow stationary planetary waves to propagate and interact with the mean flow. Thus, if planetary waves are strong enough or/and one branch of the upward SPW from high latitudes is refracted to equatorward and upward, it would encounter the critical layer in MLT region over mid-low-latitude and finally induce the winds reversal there.

In the nonlinear theory scheme, Yoden (1987) and Hu et al. (1995) analyzed the bifurcation properties of the stratosphere and mesosphere winter system with wave-forcings at the bottom boundary. They pointed out that the SSW event is a kind of catastrophe trigged by the increase of planetary wave amplitude at the bottom boundary. When the SSW event happens, the stratosphere and the mesosphere system will experience an oscillation state in which the zonal winds might reverse sometime. The observation evidences of this paper prove it is possible the first time, which suggest that the mid-low latitude mesosphere has the same major dynamics with the polar region. The mesosphere over mid-low latitude could belong to the same middle atmosphere system which is responsible for SSW events.

The results of simulation based on TIME-GCM/CCM3 by Liu and Roble (2002) did not show reversal of MLT zonal winds over mid-low latitude. The reversal of zonal wind only showed up at the high latitude between 40 and $80 \mathrm{~km}$, while the MLT wind over mid-low-latitude was still a strong eastward wind during that SSW event. But the zonal mean wind between 50 and $80 \mathrm{~km}$ over mid-low latitude showed a slight deceleration during the warming episode.

However, observations in different sites or in different winters during SSW events have different characteristics in details, especially about atmospheric waves. Therefore, more work needs to be carried out in order to achieve a clear and global view of the MLT response on the SSW events.

\section{Conclusion}

MF radar wind observations over Wuhan $\left(30^{\circ} \mathrm{N}, 114^{\circ} \mathrm{E}\right)$ in $2000 / 2001$ winter and over Langfang $\left(39.4^{\circ} \mathrm{N}, 116.6^{\circ} \mathrm{E}\right)$ in $2009 / 2010$ winter both showed clear response to SSW phe- nomenon. There was a consistent change in the wind pattern and some distinct feature in atmospheric waves' behaviors over Wuhan and Langfang associated with the 2001 SSW event and 2010 SSW event. The MLT zonal wind over both sites reversed from eastward wind into westward wind when the polar temperature reached maximum at $10 \mathrm{hPa}$ and the SPW1 growth at $60^{\circ} \mathrm{N}, 10 \mathrm{hPa}$. However, the reversal of zonal wind in mid-latitude MLT was about ten days prior to the zonal wind reversal at $10 \mathrm{hPa}, 60^{\circ} \mathrm{N}$. The MLT daily mean meridional wind over mid-low-latitude changed to more equatorward during SSWs, especially over Langfang (higher latitude) during 2010 SSW. These results were mostly consistent with those in high latitudes MLT.

The temporal variations of diurnal tides, semidiurnal tides, terdiurnal tides, gravity waves and 2-day waves in the midlow-latitude MLT showed different features during the two SSW events. Over Wuhan in 2000/2001 winter, the MLT diurnal tide peaked on 18 January 2001 when the stratospheric zonal wind decreased quickly and SSW event started in polar winter stratosphere; the activity of 2-day waves weakened after the onset of the $2001 \mathrm{SSW}$, while the activity of gravity enhanced when the SSW developed into a major warming. However, in the 2009/2010 winter, the semidiurnal tide and 2-day waves over Langfang peaked on 7 February 2010, about two days earlier than the zonal wind reversal at $10 \mathrm{hPa}$, $60^{\circ} \mathrm{N}$; the diurnal, terdiurnal tides and gravity waves over Langfang showed no significant features during the 2010 SSW event.

The dynamical responses of mid-latitude MLT to SSW are very complicated. The possible interactions between PW, tides and gravity waves and their contributions to the midlatitude MLT responses are not clear, and need to be investigated deeper in our future works. The current general circulation models can not reveal the observed responses of midlatitude MLT wind reversal, which suggest that models do not include all the physical processes and need to be improved in the future.

Acknowledgements. We thank Alan Z. Liu for critical comments on the manuscript. This work was supported by grants from National Natural Science Foundation of China. The Grant No. is 41104099 , 41104100 and 40774087 . The authors gratefully acknowledge the access to the NCEP data and AURA MLS data.

Topical Editor C. Jacobi thanks two anonymous referees for their help in evaluating this paper.

\section{References}

Andrews, D. G., Holton, J. R., and Leovy, C. B.: Stratospheric sudden warming, in: Middle Atmosphere Dynamics, pp. 259, Academic Press, 1987.

Azeem, S. M. I., Talaat, E. R., Sivjee, G. G., Liu, H. L., and Roble, R. G.: Observational study of the 4-day wave in the mesosphere preceding the sudden stratospheric warming 
events during 1995 and 2002, Geophys. Res. Lett., 32, L15804, doi:10.1029/2005g1023393, 2005.

Bhattacharya, Y., Shepherd, G. G., and Brown, S.: Variability of atmospheric winds and waves in the Arctic polar mesosphere during a stratospheric sudden warming, Geophys. Res. Lett., 31, L23101, doi:10.1029/2004g1020389, 2004.

Dowdy, A. J., Vincent, R. A., Tsutsumi, M., Igarashi, K., Murayama, Y., Singer, W., Murphy, D. J., and Riggin, D. M.: Polar mesosphere and lower thermosphere dynamics: 2. Response to sudden stratospheric warmings, J. Geophys. Res., 112, D17105, doi:10.1029/2006jd008127, 2007.

Haldoupis, C., Pancheva, D., and Mitchell, N. J.: A study of tidal and planetary wave periodicities present in midlatitude sporadic E layers, J. Geophys. Res., 109, A02302, doi:10.1029/2003ja010253, 2004.

Hall, C. and Aso, T.: Identification of possible ion-drag induced neutral instability in the lower thermosphere over Svalbard, Earth, Planets Space, 52, 639-643, 2000.

Hocke, K. and Igarashi, K.: Diurnal and semidiurnal tide in the upper middle atmosphere during the first year of simultaneous MF radar observations in northern and southern Japan $\left(45^{\circ} \mathrm{N}\right.$ and $\left.31^{\circ} \mathrm{N}\right)$, Ann. Geophys., 17, 405-414, doi:10.1007/s00585-9990405-x, 1999.

Hoffmann, P., Singer, W., Keuer, D., Hocking, W., Kunze, M., and Murayama, Y.: Latitudinal and longitudinal variability of mesospheric winds and temperatures during stratospheric warming events, J. Atmos. Solar-Terr. Phys., 69, 2355-2366, doi:10.1016/j.jastp.2007.06.010, 2007.

$\mathrm{Hu}, \mathrm{X}$., Zhang, X., and Huang, X.: Bifurcation properties of a stratospheric vacilation model, Acta Geophysica Sinica, 38, 428-438, 1995.

Hu, X., Zhang, X., Igarashi, K., and Zhang, D.: A preliminary comparison of observations with MF radars in Wuhan and Yamagawa at 30-31 ${ }^{\circ}$ N, J. Atmos. Solar-Terr. Phys., 68, 1036-1042, 2006.

Jacobi, C., Kurschner, D., Muller, H. G., Pancheva, D., Mitchell, N. J., and Naujokat, B.: Response of the mesopause region dynamics to the February 2001 stratospheric warming, J. Atmos. SolarTerr. Phys., 65, 843-855, doi:10.1016/S1364-6826(03)00086-5, 2003.

Jiang, G., Xu, J., and Franke, S. J.: The 8-h tide in the mesosphere and lower thermosphere over Maui $\left(20.75^{\circ} \mathrm{N}, 156.43^{\circ} \mathrm{W}\right)$, Ann. Geophys., 27, 1989-1999, doi:10.5194/angeo-27-19892009, 2009.

Kovalam, S. and Vincent, R. A.: Intradiurnal wind variations in the midlatitude and high-latitude mesosphere and lower thermosphere, J. Geophys. Res., 108, 4135, doi:10.1029/2002jd002500, 2003.

Li, F., Hu, X., Zhang, D. Y., Zhang, X. J., Huang, Z. R., Xiong, J. G., and Zeng, Z.: Mesospheric MF radar in Wuhan and its preliminary observation results, Chinese Journal of Space Science, 22, 65-71, 2002.

Liu, H.-L. and Roble, R. G.: A study of a self-generated stratospheric sudden warming and its mesospheric-lower thermospheric impacts using the coupled TIME-GCM/CCM3, J. Geophys. Res.-Atmos., 107, 4695, doi:10.1029/2001JD001533, 2002.

Matsuno, T.: Vertical Propagation of Stationary Planetary Waves in the Winter Northern Hemisphere, J. Atmos. Sci., 27, 871-883, 1970.
Matsuno, T.: Dynamical Model of Stratospheric Sudden Warming, J. Atmos. Sci., 28, 1479-1494, 1971.

Meriwether, J. W. and Gerrard, A. J.: Mesosphere inversion layers and stratosphere temperature enhancements, Rev. Geophys., 42 Rg3003, doi:10.1029/2003rg000133, 2004.

Nozawa, S., Brekke, A., Manson, A., Hall, C., Meek, C., Morise, K., Oyama, S., Dobashi, K., and Fujii, R.: A comparison study of the auroral lower thermospheric neutral winds derived by the EISCAT UHF radar and the Troms $\emptyset$ medium frequency radar, J Geophys. Res., 107, 1216, doi:10.1029/2000JA007581, 2002.

Oyama, S., Kurihara, J., Watkins, B. J., Tsuda, T. T., and Takahashi, T.: Temporal variations of the ion-neutral collision frequency from EISCAT observations in the polar lower ionosphere during periods of geomagnetic disturbances, J. Geophys. Res., 117, A05308, doi:10.1029/2011ja017159, 2012.

Oznovich, I., McEwen, D. J., Sivjee, G. G., and Walterscheid, R. L.: Tidal oscillations of the Arctic upper mesosphere and lower thermosphere in winter, J. Geophys. Res., 102, 4511-4520, doi:10.1029/96ja03560, 1997.

Reid, G. C.: The influence of electric fields on radar measurements of winds in the upper mesosphere, Radio Sci., 18, 1028-1034, doi:10.1029/RS018i006p01028, 1983.

Remsberg, E., Lingenfelser, G., Harvey, V. L., Grose, W., Russell III, J., Mlynczak, M., Gordley, L., and Marshall, B. T.: On the verification of the quality of SABER temperature, geopotential height, and wind fields by comparison with Met Office assimilated analyses, J. Geophys. Res., 108, 4628, doi:10.1029/2003jd003720, 2003.

Sathishkumar, S. and Sridharan, S.: Planetary and gravity waves in the mesosphere and lower thermosphere region over Tirunelveli $\left(8.7^{\circ} \mathrm{N}, 77.8^{\circ} \mathrm{E}\right)$ during stratospheric warming events, Geophys. Res. Lett., 36, doi:10.1029/2008g1037081, 2009.

Sathishkumar, S., Sridharan, S., and Jacobi, C.: Dynamical response of low-latitude middle atmosphere to major sudden stratospheric warming events, J. Atmos. Solar-Terr. Phys., 71, 857-865, 2009.

Scherhag, R.: Die explosionsartige Stratosphärenerwarmung des Spätwinters 1951/52, Ber. Deut. Wetterdienstes, 6, 51-63, 1952.

Shepherd, M. G., Wu, D. L., Fedulina, I. N., Gurubaran, S., Russell, J. M., Mlynczak, M. G., and Shepherd, G. G.: Stratospheric warming effects on the tropical mesospheric temperature field, J. Atmos. Solar-Terr. Phys., 69, 2309-2337, 2007.

Smith, A. K., Pancheva, D. V., and Mitchell, N. J.: Observations and modeling of the 6-hour tide in the upper mesosphere, J. Geophys. Res., 109, D10105, doi:10.1029/2003jd004421, 2004.

Wang, L. and Alexander, M. J.: Gravity wave activity during stratospheric sudden warmings in the 2007-2008 Northern Hemisphere winter, J. Geophys. Res., 114, D18108, doi:10.1029/2009jd011867, 2009.

Xiao, C. Y., Hu, X., and Tian, J. H.: Analysis and comparison of deriving winds from satellite temperature data, Chinese Journal of Geophysics, 51, 325-336, 2008.

Yoden, S.: Bifurcation properties of a stratospheric vacillation model, J. Atmos. Sci., 44, 1723-1733, 1987.

Zhang, S. D., Yi, F., and Hu, X.: MF radar observation of mean wind and tides of winter mesopause $(80-98 \mathrm{~km})$ region over Wuhan (30 degrees N, 114 degrees E), J. Atmos. Solar-Terr. Phys., 66, 15-25, doi:10.1016/j.jastp.2003.10.006, 2004. 